\title{
Trichoderma virens Mediated Rock Phosphate Solubilization: A Potential Replacement For Triple Super Phosphate in Rice Cultivation
}

\author{
Dilani P.V.D. ${ }^{1 *}$, Nanayakkara C.M. ${ }^{1}$ and Sirisena D.N. ${ }^{2}$ \\ ${ }^{1}$ University of Colombo, Sri Lanka \\ ${ }^{2}$ Rice Research and Development institute, sri lanka \\ *deshdilpadukka@gmail.com
}

\begin{abstract}
Annually, Sri Lanka spends 20 billion Rupees to import Triple super Phosphate (TSP) mainly for the rice cultivation. It has been recorded that, significantly high arsenic content is present in imported TSP compared to Eppawala Rock phosphate (ERP). Further, the current understanding is that arsenic is among the major etiological agents of Chronic Kidney Disease. Hence, a progressive reduction in the use of TSP in rice cultivation may help in reducing health and environmental problems associated with it. Yet the major constraint in the use of ERP in rice cultivation is its low solubility. As microorganisms are efficient solubilizers of Rock phosphate, attempts were made to employ a local isolate of Trichodrema virens, which has a proven track record for ERP solubilization, to increase the solubility of ERP with the aim of developing an environmentally friendly liquid $\mathrm{P}$ fertilizer.

A pot experiment was conducted at Rice Research and Development Institute at Batalagoda. An amended Pikovskaya (PVK) medium with ERP was inoculated with T. virens containing $1 \mathrm{X} 106 \mathrm{spores} / \mathrm{ml}$ and incubated at $100 \mathrm{rpm}$ oscillation until maximum solubilized $\mathrm{P}$ content was obtained. The filtered and autoclaved culture filtrate was applied to the rice variety $\mathrm{Bg} 250$ one week before transplanting. Fertilizer application included: Control without any fertilizer (C1), control with recommended level of MOP, urea and no P (C2), Control with PVK medium without $\mathrm{P}$ source (C3), TSP at recommended level (P1), TSP at half recommended level together with developed fertilizer added to replace half recommended level of TSP quantitatively (P2), TSP at half recommended level (P3), developed fertilizer applied at recommended level of TSP (P4). Additionally, the recommended level of MOP and Urea was applied to every treatment except for $\mathrm{C} 1$. Completely randomized design was employed with 12 replicates and each pot containing 4 rice plants. Plant growth parameters and plant and soil $\mathrm{P}$ contents were quantitatively determined by destructive sampling of 04 replicates from each treatment at tillering stage and at 50\% flowering stage while yield parameters with plant and soil $\mathrm{P}$ were measured at harvesting stage. The results obtained were analyzed using $\mathrm{T}$ test and one way ANOVA. During fertilizer development, maximum P content (42.55 mg P/l) was obtained at 72 hour post incubation. All the studied parameters differed significantly among treatments $(\mathrm{P}=0.000)$. Superior growth and yield performance were shown by $\mathrm{P} 2$ where the performance was not significantly different from that of P1 for all the tested parameters. Even though treatment P4 was not superior to treatment P1, it was significantly superior to P3. Hence, the data suggests the possibility of reducing the recommended level of TSP into half by using the developed liquid fertilizer to minimize TSP usage.
\end{abstract}

Keywords: Trichodrema virens, Phosphorus, Eppawala rock phosphate, Rice, Growth parameters, Yield parameters

Proceedings of the International Forestry and Environment Symposium 2016, Department of Forestry and Environmental Science, University of Sri Jayewardenepura, Sri Lanka. 